\title{
DILEMA INIMAGINÁ VEL PARA OS DIREITOS HUMANOS: A PERIGOSA ONDA DESGLOBALIZANTE, NACIONALISTA E XENÓFOBA EM PLENA ERA DIGITAL
}

\author{
UNIMAGINABLE DILEMMA FOR HUMAN RIGHTS: THE DANGEROUS WAVE \\ DEGLOBALIZING, NATIONALIST AND XENOPHOBIC IN THE DIGITAL AGE
}

\author{
${ }^{1}$ Laécio Noronha Xavier
}

\section{RESUMO}

A Organização das Nações Unidas, a Declaração Universal dos Direitos Humanos e a União Europeia representam os arquétipos jurídicos civilizatórios do século XX. Decorrente dessa síntese evolutiva o mundo assistiu três eventos-fenômenos a partir dos anos1980: a queda do Muro do Berlim, com vitória da cultura política ocidental; a era digital, cujas inovações tecnológicas alteraram substancialmente a sociedade; e a globalização, integrando nações em processos econômicos igualitários. Todavia, o "gráfico do elefante" e a saída do Reino Unido da União Europeia criaram um cenário desglobalizante inimaginável pondo em risco a democracia, os direitos humanos e a unidade dos mercados.

Palavras-chave: Direitos Humanos; Desglobalização; Nacionalismo; Xenfobia; Era Digital.

\begin{abstract}
The United Nations, the Universal Declaration of Human Rights and the European Union represent the civilizational legal archetypes of the twentieth century. Due to this evolutionary synthesis the world witnessed three events-phenomena from 1980's: the fall of the Berlim Wall, with victory western political culture; the digital age, who technological innovations fundamentally altered society; and globalization, integrating nations egalitarian economic processes. However, the "elephantgraphic"and the output of the United Kingdom of the European Union created a deglobalizing unimaginable scenario endangering democracy, human rights and the unity of markets.
\end{abstract}

Keywords: Human Rights; Deglobalization; Nationalism; Xenophobia; Digital Age.

\footnotetext{
${ }^{1}$ Doutor em Direito Público pela Universidade Federal de Pernambuco - UFPE, Pernambuco (Brasil). Professor de Direito Internacional Público pela Universidade de Fortaleza - UNIFOR, Ceará (Brasil). E-mail: laecio.interagir@ibest.com.br
} 


\section{INTRODUÇÃO}

$\mathrm{O}$ artigo tem como temática central demonstrar como as nações, a partir do final da II Guerra Mundial, moldaram os "arquétipos jurídicos civilizatórios" do século XX, através da criação da Organização das Nações Unidas (ONU) e assinatura da Carta das Nações Unidas em 1945, rearticulando uma sociedade internacional de nações em substituição a Liga das Nações; da proclamação em 1948 da Declaração Universal dos Direitos Humanos (DUDH) representando o marco do constitucionalismo contemporâneo; e da integração econômica e política da Europa, em 1951, com assinatura de tratados energéticos entre França, Alemanha, Itália, Bélgica, Holanda e Luxemburgo.

Em relação aos objetivos da investigação busca-se examinar os principais "eventosfenômenos" decorrentes desses "arquétipos jurídicos civilizatórios", como: a queda do Muro do Berlim (1989), representando a vitória dos pilares da cultura política ocidental (democracia representativa, economia de mercado, direitos humanos, desenvolvimento sustentável, responsabilidade fiscal, ética, secularismo, inovação científico-tecnológica); o ingresso na era digital, cujas inovações tecnológicas pós-1980 alteraram substancialmente os padrões comportamentais da sociedade; e a globalização impulsionada pela integração mundial das nações em processos econômicos igualitários desde os anos 1990.

Todavia, tal "cenário de idealidade" dos últimos 25 anos com consolidação universal dos valores políticos ocidentais, novos formatos tecnológicos e comunicacionais, e integração regional e global de mercados começou a sucumbir com os efeitos da "desglobalização". A pesquisa tem como justificativa identificar nos dados apresentados pelo "gráfico do elefante" um dilema inimaginável para a democracia, os direitos humanos e a unidade dos mercados nesse breve século XXI. Ou seja, ao contrário dos países periféricos, emergentes e classes altas dos países desenvolvidos, foram as classes média e baixa dos países desenvolvidos que tiveram perdas econômicas com a globalização, fato que fez pulsar seu espírito nacionalista e xenófobo, através da antipolítica (ou anti-establishment) e do ódio aos estrangeiros. 
A integração europeia, em especial, assegurou um continente sem fronteiras nacionais, belicismo e barreiras comerciais, expondo o maior legado da Europa para a "paz universal”. E desde 1950 tudo vinha dando certo nesse processo integrativo político, econômico e de cidadania comum. Entretanto, a retirada do Reino Unido da União Europeia ou Brexit, o acrônimo de Britain e exit (saída), faz surgir a problematização teórica denotando um significado geopolítico monumental: o Brexit pode ser o estopim para anular parcialmente a utopia de um mundo sem fronteiras, lançar Reino Unido e Europa num período de incertezas econômicas e políticas, suscitar perigosa onda desintegracionista no continente, e ampliar o espírito nacionalista e anti-imigratório de suas nações com atos de xenofobia e ódios raciais levando o respeito universal aos direitos humanos a um dilema historicamente inimaginável.

E sob o prisma metodológico, o ensaio ordena-se pelos seguintes procedimentos e etapas: i) Histórico-descritivo - identificar os "arquétipos jurídicos civilizatórios" que moldaram as nações no século XX; ii) Sistêmico-conceitual - analisar os "eventosfenômenos" ocorridos a partir dos anos 1980, como a vitória dos valores da cultura política ocidental, a inovação científico-tecnológica da era digital e a integração mundial dos mercados; iii) Analítico-interpretativo - expor o dilema da democracia e dos direitos humanos no século XXI em face dos movimentos antí-política em várias partes do mundo, em especial, o Brexit. E no patamar das fontes referenciais listam-se compêndios teóricos pátrios e estrangeiros, materiais informativos e pesquisas acadêmicas nas áreas do Direito Constitucional, Direito Internacional Público, Ciência Política e Economia Política.

\section{ARQUÉTIPOS JURÍDICOS CIVILIZATÓRIOS QUE SINTETIZAM A EVOLUÇÃO HUMANA NO SÉCULO XX}

O primeiro "arquétipo jurídico civilizatório" foi a criação de duas associações internacionais de nações com status de governo mundial nos períodos posteriores as I e II guerras mundiais. Com o Tratado de Versailles/1919, foi proposto a instalação de um ente internacional destinado a transformar a condução das relações exteriores, de modo a evitar a repetição de agressões internacionais, oferecer garantias mútuas de independência 
política, defender a integridade territorial, arbitrar conflitos e manter a paz entre as nações. Era a "nova diplomacia" idealizada pelo presidente americano Woodrow Wilson, o ministro britânico das Relações Exteriores Robert Cecil, e o primeiro-ministro sulafricano Jan Smuts. Instalou-se, assim, em 28 de junho de 1919, em Versailles, a Liga das Nações com declaração subscrita por 44 países e sede em Genebra/Suíça. (HENIG, 1991).

A Liga das Nações foi organizada com um Secretariado Permanente, órgão administrativo com corpo de especialistas e liderado por um Secretário Geral; Conselho Executivo formado por 09 membros, dos quais 05 permanentes (Estados Unidos, França, Itália, Japão, Inglaterra) e 04 não permanentes eleitos mediante voto, rodízio continental e determinado período; e Assembléia Geral que reunia anualmente os representantes de todos os Estados com direito a igual voto. Todavia, a Liga adotou um modelo de deliberação para o Conselho Executivo e a Assembléia Geral em que as votações sobre temas de grande importância se davam por unanimidade, inviabilizando a resolução dos problemas internacionais relevantes. Vale menção, que o Brasil foi membro fundador da Liga. Porém, em 1924, durante o governo do presidente Artur Bernardes, ao pleitear uma vaga permanente no Conselho Executivo, o Brasil recusou o ingresso da Alemanha para os mesmos cargo e órgão. E o efeito diplomático imediato foi o isolamento do Brasil na Liga das Nações, findando, em 1926, no abandono da organização. (CERVO \& BUENO, 1992).

Apesar dos esforços do presidente Wilson (Partido Democrata), o Congresso americano, dominado por republicanos, não aceitou associar-se à Liga das Nações, que não contou, inicialmente, com a participação da União das Repúblicas Socialistas Soviéticas (URSS), Alemanha, Japão e Turquia. Ademais, a Liga também não contava com representação de metade da população mundial que vivia em países coloniais (KISSINGER, 2001). E a mediação de conflitos e os apelos em favor da paz não foram suficientes para evitar novas confrontações bélicas internacionais. Como não dispunha de corpo militar, estrutura econômica e regras universais antibelicistas para intervir em áreas de conflito, manter situações de paz e/ou impor punições aos países conflitantes, as ferramentas de coerção da Liga baseavam-se quase que exclusivamente em sanções morais (VIANNA \& MOREIRA, 2001). O papel limitado da Liga no período entreguerras (1918-1939) é referendado pelos atritos entre as potências e suas colônias, em 
especial, a invasão japonesa à Manchúria/China em 1931, a segunda guerra entre Itália e Abissínia (atual Etiópia) em1935-1936, e a invasão da Polônia pela Alemanha em 1939. Ou seja, criou-se um terreno fértil para a II Guerra Mundial (1939-1945), assinalando-se o início do fim da Liga. (KENNEDY, 2006).

A Liga das Nações funcionou oficialmente de janeiro/1920, data da primeira reunião do Conselho em Paris, até abril/1946, sua última Assembleia, em Genebra, quando foi declarada sua dissolução. Contudo, somente deixou definitivamente de existir em julho/1947, com o encerramento de suas contas pelo comitê de liquidação. E como a ONU teve sua carta constitutiva aprovada na Conferência de São Francisco, em outubro/1945, não se trata o caso de a ONU ter sucedido à Liga. Mas, de ter encampado iguais objetivos, acolhido os bens que foram transferidos para seu patrimônio, e mantido em sua estrutura diretiva dois órgãos autônomos da Liga: a Organização Internacional do Trabalho - OIT e a Corte Permanente de Justiça Internacional - CPJI. (AZEVEDO, 1982).

A criação da ONU deu-se como resultado das conferências de paz realizadas no final da II Guerra Mundial, quando as 51 maiores nações (exceto Alemanha, Itália, Japão) aceitaram os 111 artigos da Carta das Nações Unidas. Em seu preâmbulo, a Carta aduz sobre as gerações vindouras evitarem a guerra e manterem a paz internacional. E para esses fins as nações devem tomar medidas coletivas, eficazes e pacíficas em conformidade com os princípios da justiça e do direito internacional para solucionar controvérsias e prevenir/reprimir agressões internacionais. Composta por 193 Estadosmembros (atualmente), a ONU tem sede geral em Nova York/EUA, sede europeia em Genebra/Suíça e escritórios regionais em Viena/Áustria, Adis Abeba/Etiópia, Beirute/Líbano, Bangkok/Tailândia e Santiago/Chile, com todas as áreas e prédios representando "território internacional”. A ONU utiliza o Francês e o Inglês como línguas oficiais prioritárias de trabalho, e o Árabe, Chinês, Espanhol e Russo como línguas oficiais complementares. (KISSINGER, 2001).

São órgãos principais da ONU: Assembleia Geral que se reúne anualmente em setembro em Nova York com todos os países-membros; Conselho de Segurança formado por 05 membros permanentes (EUA, Inglaterra, França, Rússia, China) e mais 10 membros provisórios eleitos bianualmente; Secretariado presidido pelo Secretário-Geral 
com mandato de 05 anos e atribuição de administrar e organizar a instituição; Conselho Econômico e Social com 54 membros (mandato de 03 anos) para promoverem a cooperação internacional econômica e social; e Corte Internacional de Justiça, sucessor da CPJI, órgão judicial e consultivo da ONU para dirimir os litígios entre Estados, como interferências estatais ilegais e problemas nos territórios nacionais e em águas internacionais. (FASULO, 2009).

São órgãos auxiliares especializados da ONU (FASULO, 2009): Conselho de Direitos Humanos das Nações Unidas (UNHRC), Organização das Nações Unidas para a Alimentação e a Agricultura (FAO), Programa Alimentar Mundial (PAM), Agência Internacional de Energia Atômica (AIEA), Organização da Aviação Civil Internacional (OACI), Fundo Internacional de Desenvolvimento Agrícola (IFAD), Organização Internacional do Trabalho (OIT), Organização Mundial do Comércio (OMC), Organização Marítima Internacional (OMI), Fundo Monetário Internacional (FMI), Banco Mundial (BM), Organização para a Educação, a Ciência e a Cultura (UNESCO), Organização para o Desenvolvimento Industrial (UNIDO), União Internacional de Telecomunicações (UIT), União Postal Universal (UPU), Organização Mundial da Saúde (OMS), Organização Mundial da Propriedade Intelectual (OMPI), Organização Meteorológica Mundial(OMM) e Organização Mundial do Turismo (OMT). Desses órgãos especializados da ONU, a FAO e a OMC estão, atualmente, sendo dirigidos pelos brasileiros José Graziano e Roberto Azevedo.

O objetivo da ONU é unir todas as nações em prol da paz e do desenvolvimento, com base nos princípios da justiça, dignidade humana e bem-estar dos povos, dando aos países a oportunidade de solucionar problemas considerando a interdependência mundial e os interesses nacionais. Apesar da pretensão de participação igual dos países, a ONU deu peso maior aos EUA e Rússia, em virtude de seus papéis preferenciais na resolução de conflitos militares. Ao longo da história, a ONU colecionou reveses na mediação de desentendimentos entre países, mas, por outro lado, exerceu relevante papel em seu “objetivo primário” de garantir a paz e a segurança das nações. (COULON, 1998).

Durante a Guerra Fria, a ONU aprovou uma resolução para dividir a Palestina, criando o Estado de Israel em 1947, e em 1949, negociou um armistício para o conflito 
resultante. Em 1950 autorizou coalizão liderada pelos EUA a revogar a invasão da Coréia do Norte à Coréia do Sul. Em 1956, deu-se a primeira ação de sua Força de Manutenção de Paz em Suez, quando Israel, com apoio da França e Reino Unido, que utilizavam e controlavam o canal no comércio oriental, declarou guerra ao Egito, cujo presidente (Nasser) havia nacionalizado o canal. Porém, no mesmo ano, a ONU foi incapaz de intervir na invasão da URSS à Hungria. Entre 1960-1964, outra ação da Força de Manutenção de Paz trouxe ordem à República do Congo. Todavia, a ineficiência em mediar conflitos no Oriente Médio, Vietnã e Caxemira e as ditaduras militares na América Latina nos anos 1970 fizeram com que a ONU deslocasse seu orçamento para os "objetivos secundários" (desenvolvimento econômico e social e intercâmbio cultural), ultrapassando os recursos financeiros aportados nas Forças de Manutenção da Paz. (MEISLER, 1995).

Paradoxalmente, com o fim da Guerra Fria, a ONU expandiu radicalmente suas missões de paz entre 1988-2000, superando as quatro décadas anteriores, mais que dobrando as resoluções do Conselho de Segurança, e aumentando seu orçamento em dez vezes. A ONU lançou missões na guerra de independência da Namíbia (1966-1988), negociou o fim da Guerra Civil de El Salvador (1980-1992), supervisionou as eleições na África do Sul pós-apartheid (1994) e no Camboja pós-Khmer Vermelho (1998). Em 1991, autorizou coalizão liderada pelos EUA a repelir a invasão iraquiana no Kuwait. Entretanto, a ONU enfrentou nesse período várias crises, como as ações fracassadas na Somália, Haiti, Moçambique, Ruanda e Bósnia. Já nas décadas seguintes as missões da ONU atuaram diferentemente na Guerra Civil de Serra Leoa (1991-2002), quando foram apoiadas pelos marines britânicos, na invasão do Afeganistão em 2001, que foi supervisionada pela OTAN, e durante a Guerra Civil na Síria, que recebeu auxílio dos inspetores internacionais de armas químicas. A ONU também interveio nos conflitos do Sudão (2003-2014), República do Congo (2004-2009) e Sri Lanka (2009). Contudo, em 2003, os EUA invadiram o Iraque sem aval do Conselho de Segurança, levando a novos questionamentos sobre a eficiência da ONU. (MIRES, 2013).

O segundo "arquétipo jurídico civilizatório" advém da Declaração Universal dos Direitos Humanos, o liame histórico-jurídico do processo de constitucionalização dos Direitos Humanos pelas nações. A incorporação dos 30 artigos da DUDH pelos 
ordenamentos jurídicos da maioria da comunidade internacional constituiu-se no mais bem-sucedido projeto mundial de consenso político e na maior referência para o constitucionalismo contemporâneo. Os dispositivos da DUDH-ONU/1948 funcionam como princípios universalizantes de aferição de governos libertários e de critérios para sociedades justas, livres e solidárias, e firmam a máxima Não existe vida inteligente fora da Democracia. Nenhum Estado ou Bloco Comunitário pode almejar ser considerado democrático, caso não tenha recepcionado tais cânones da convivência política plural, tolerante e inclusiva. (XAVIER, 2012).

A DUDH (Resolução 217-A III) foi proclamada por 48 países na Assembleia Geral da ONU em Paris (dezembro/1948), como norma comum a ser alcançada por todos os povos e nações. A DUDH em conjunto com o Pacto Internacional dos Direitos Civis e Políticos/1966 e o Pacto Internacional dos Direitos Econômicos, Sociais e Culturais/1992 formam a Carta Internacional dos Direitos Humanos, além de uma série de tratados que expandiram o corpo do Direito Internacional dos Direitos Humanos, como as convenções para Prevenção e Repressão do Crime de Genocídio/1948, Eliminação de Todas as Formas de Discriminação contra as Mulheres/1979, Direitos da Criança/1989 e Direitos das Pessoas com Deficiência/2006. (MÖLLER, 2008).

A DUDH serviu de inspiração principiológica e positiva para o Estado Democrático de Direito, realçando uma envergadura inédita de direitos, liberdades e garantias com materialização de práticas institucionais de tratamento equânime para todas as pessoas em quaisquer circunstâncias e localidades. O exercício da Democracia pressupõe inapelavelmente o respeito aos temas dos Direitos Humanos traduzidos, especialmente, na positivação dos Princípios Gerais do Direito: todos são iguais perante a lei, sem distinção de qualquer natureza; ninguém deverá ser obrigado a fazer ou deixar de fazer alguma coisa senão em virtude de lei; todos têm direito ao devido processo legal, assegurando-se o contraditório e a ampla defesa; são vedadas as penas cruéis, de tortura e retroativas. (XAVIER, 2012).

Fundado na concepção “jusnaturalista” que abraça os contextos históricos e socioculturais da humanidade, todo ser humano, na contemporaneidade, tornou-se portador de direitos e garantias, independendo juridicamente da previsão "positivista" de 
ação estatal. Identificados enquanto "Liberdades Públicas", cabe a todo cidadão exigir que o Estado as reconheça em seus ordenamentos jurídicos e garanta os meios institucionais de atendimento de suas prerrogativas e que a sociedade respeite a "dignidade da pessoa humana" como ideal político e premissa para o estabelecimento da democracia e civilidade, com os Direitos Humanos alicerçados nos princípios da historicidade, universalidade, imprescritibilidade, irrenunciabilidade, inalienabilidade, inviolabilidade, efetividade, concorrência, interdependência e complementaridade. A DUDH é uma referência global que vincula os Estados à obrigação de positivar em suas constituições um sistema de valores que acarreta num conjunto de direitos fundamentais de caráter natural, tutelando a vida, igualdade, liberdade, propriedade e segurança. (BONAVIDES, 1994).

O terceiro "arquétipo jurídico civilizatório" que moldou a humanidade no século XX foi o legado da integração europeia, tese advinda da articulação de várias personalidades no pós-Guerra para frear as frequentes guerras no continente. E dentre os personagens que fundaram a Europa integrada, em paz, unida e próspera elenca-se: Robert Schuman, Jean Monnet, Winston Churchill, Konrad Adenauer, Altiero Spinelli, Paul-Henri Spaak, Joseph Bech, Alcide De Gasperi, Walter Hallstein e Sicco Mansholt. Desde 1951, quando foram celebradas as convenções europeias de Energia Atômica e do Carvão e Aço, o BENELUX (Bélgica, Holanda, Luxemburgo) mais França, Alemanha, Itália iniciaram o "edifício europeu" ao cambiarem rivalidades históricas pela fusão de interesses comuns. Em 1957, o Tratado de Roma instituiu a Comunidade Econômica Europeia ou Mercado Comum, consolidando o percurso histórico-institucional do maior bloco comunitário do planeta, solidificando-se como União Político-Econômica nos anos 1990. (SEINTEFUS, 1997).

A União Europeia é única em termos de estrutura, metodologia e composição. A Alta Autoridade do comunitarismo europeu é exercida por instituições supranacionais (ou acima dos estados), como Parlamento, Conselho e Comissão, fazendo com que os estados trafeguem juridicamente com 05 (cinco) competências nacionais: abolidas, transferidas, delimitadas, coordenadas e reservadas (SIMON, 1998). A constitucionalização da Europa constituiu uma transformação na natureza da Comunidade via substituição infraconstitucional e modificação da força vinculante dos Tratados Internacionais, 
passando de um sistema constitucional-internacionalista dualista, dependente de recepção nacional das regras contidas em Tratados, para um sistema constitucionalinternacionalista unitário (MANCINI, 1989). E no âmbito das competências comunitárias, o Direito Comunitário superpõe-se ao Direito Nacional e produz efeitos diretos e indiretos, através de uma teia de fatos jurídicos políticos e econômicos que ampliou a solidariedade fática e a vinculação de diferentes países. (WARD, 1996).

A unidade das nações foi o maior legado da Europa para o mundo. A integração europeia assegurou as bases da "paz universal" e a cidadania comum ao eliminar o belicismo, abjurar os ódios nacionais e construir um continente sem fronteiras e barreiras. E tudo vinha dando certo no processo integrativo, pelo menos até surgirem os efeitos da “desglobalização" nas primeiras décadas do século XXI. Especialmente, com a retirada do Reino Unido da União Europeia (Brexit), fato que denota um significado geopolítico monumental, uma vez que finda parcialmente com a utopia de um mundo sem fronteiras, lança Reino Unido e Europa num período de incertezas econômicas e políticas, e pode suscitar uma perigosa onda desglobalizante e desintegracionista no continente e no mundo.

\section{EVENTOS-FENÔMENOS PÓS-SÉCULO ESPECIAL: MURO DE BERLIM, GLOBALIZAÇÃO E ERA DIGITAL}

A instalação da ONU, a proclamação da DUDH e a integração europeia representam os "arquétipos jurídicos civilizatórios” advindos do pós-II Guerra Mundial e que inspiraram os "eventos-fenômenos" que mudaram o mundo, como a queda do Muro de Berlim simbolizando a virada política universalizante dos valores ocidentais em 1989; a globalização traduzida na liberdade econômica dos mercados nacionais; e a era digital, o período-referência das transformações tecnológicas e comunicacionais que "linkaram" o planeta.

A queda do Muro de Berlim, que anunciou o final da Guerra Fria entre capitalismo e socialismo (1945-1989), coincidiu historicamente com o processo de globalização e o início da era digital. E sob o ponto de vista das inovações tecnológicas implicando em 
avanços econômicos, a história pode ser classificada em quatro revoluções. No final do século XVIII, ocorreu a $1^{\text {a }}$ Revolução Industrial na Inglaterra com a invenção das máquinas industriais alimentadas por água a vapor, transformando a indústria e o mercado de trabalho. No fim do século XIX surge a $2^{\mathrm{a}}$ Revolução Industrial com o aparecimento de máquinas mais potentes e linhas de montagem em massa, ampliando a produção e o consumo. A $3^{\text {a }}$ Revolução Industrial acontece nos anos 1970 com a introdução dos computadores, internet e softwares possibilitando a automação computacional e a robótica, iniciando, assim, a primeira fase da era digital, da informação ou da tecnologia. Essas inovações tiveram grande impacto na sociedade e representaram um forte ganho de produtividade, contribuindo com o aumento do PIB per capita global e dos índices de desenvolvimento, como ampliação da expectativa de vida, e das taxas de emprego e renda, saneamento e acesso à cultura. (FERRARI, 2016).

As transformações tecnológicas e culturais da primeira fase da era digital posicionaram os fluxos de conteúdo comunicacional em diferentes suportes. $\mathrm{O}$ uso de mídias e plataformas digitais tornou-se tarefa obrigatória para o contato com qualquer público. A participação colaborativa dos usuários modificou as relações de poder sobre a informação gerando uma "cultura da convergência" pela confluência midiática, inteligência coletiva e cultura participativa. A cultura do "gratuito" na internet e redes sociais alterou a evolução das pessoas, das empresas e entes estatais através da força de trabalho virtual. Toda uma economia baseada no conceito de gratuidade foi impulsionada pelas comodidades trazidas pela internet no acesso às informações. E as implicações desses novos modelos de negócios do mercado free tendem a tomar mais espaço no futuro, como se a humanidade estivesse desperdiçando a internet e/ou tempo na internet. Afinal todo produto concebido digitalmente pode ser oferecido de graça, e metade da população adulta mundial atual passa mais tempo conectada na internet do que desconectada. Pode-se desfrutar da tecnologia gratuita ou não, mas é fundamental que não se perca o senso humano. $\mathrm{Na}$ era digital é preciso que os homens dominem as máquinas, sob pena de serem dominados por elas. (JENKINS, 2009).

Já a $4^{\text {a }}$ Revolução Industrial teve inicio em 2015 e marca a segunda fase da era digital, com a fusão de tecnologias das esferas físicas, digitais e biológicas através da “internet industrial”. São exemplos, a impressora 3D que imprime materiais como 
plástico, borracha e gesso ao invés de tinta no papel, permitindo a customização dos produtos; os óculos que visualizam tridimensionalmente os objetos em escala real ou ampliada e facilitam o processo produtivo com protótipos virtuais que antecipam erros e evitam descartes de materiais; a internet das coisas em que objetos físicos e virtuais são interligados e controlados por tecnologias embarcadas nos produtos; os veículos, tratores e máquinas guiados por sensores que percebem os ambientes externos, desempenhos e defeitos sem necessidade de motoristas ou operadores; o aprendizado automático das máquinas com programação que detecta os algoritmos com padrões e respostas para diferentes questões; a universalização das energias renováveis com aparelhos e sensores que aperfeiçoam o uso da água e sua dessalinização, ventos, raios solares e energia elétrica para indústria, residências, veículos e máquinas; e o Big Data, o processamento e análise de grandes volumes de dados estruturados, coletados ou interceptados por softwares para cruzar informações, detectar padrões, definir comportamentos e auxiliar nas decisões empresariais e públicas. (SCHWAB, 2016).

Entretanto, é fato inegável à miríade de invenções que vieram à luz entre $1870 \mathrm{e}$ 1970, tratar-se tal período de um "século especial", com os resultados da simultaneidade de inovações tecnológicas tendo alterado de tal forma os moldes estruturais da economia e os padrões comportamentais da sociedade, que mesmo os avanços tecnológicos patrocinados pelas duas fases da "era digital" manifestam menor impacto do que historicamente teve o surgimento do automóvel, avião, televisão, ou ar-condicionado. As inovações da era digital nas últimas décadas, como bebidas, perfumes, roupas e sapatos customizados, aplicativos para celular, e vídeos que se autodestroem em 30 segundos, são tímidas quando comparadas às invenções tecnológicas do "século especial”. (GORDON, 2016).

Contudo, historicamente, a era digital inspirou o processo de globalização que foi impulsionada por uma dupla coincidência: a consolidação dos pilares da cultura política ocidental, como democracia representativa, economia de mercado, direitos humanos, desenvolvimento sustentável, responsabilidade fiscal, ética, secularismo, inovação científico-tecnológica; e a integração das nações em espaços institucionais econômicos e políticos comuns. A globalização é uma inevitabilidade histórica que diluiu (e não concentrou) poderes entre os países desenvolvidos, emergentes e periféricos. Ao longo 
das últimas décadas, vários “episódios exitosos” mundiais na política, economia e tecnologia contribuíram para que a globalização oferecesse condições mais igualitárias de disputa às nações e empresas representando os modeladores dos cenários globais do século XXI. Índia e China são vanguardas dessa "planificação do mundo", o que lhes garantiu oportunidades de competir em mercados antes reservados a americanos e europeus. O resultado da adesão à globalização é o aumento de oportunidades de crescimento econômico para as nações e a mudança cultural das empresas, que passaram a ser competidoras num mercado incomensuravelmente mais amplo do que os nichos geográficos onde estavam inseridas. E desde que disponha de mão-de-obra qualificada, qualquer país pode utilizar a infra-estrutura global de comunicação para conquistar empregos na área de tecnologia. (FRIEDMAN, 2009).

Com a globalização houve muitos ganhos políticos (universalização dos valores ocidentais) e econômicos (acesso a mercados e mão-de-obra mais barata e livre circulação de bens, serviços e capitais). Todavia, tais ganhos sofreram retrocessos nesse breve século XXI. O processo de globalização que tirou milhões da miséria e trouxe prosperidade a países asiáticos (China, Coréia do Sul, Tailândia, Singapura, Vietnã), ceifou vários empregos entre as classes média e baixa dos países desenvolvidos. O fenômeno da globalização que abriu mercados em todo o mundo impulsionou o aumento da imigração, provocou perdas de competitividade em indústrias tradicionais e grandes crises de identidade nacional. A mesma globalização que tanto facilitou a transferência mundial de cidadãos, também recriou crises de xenofobia que pareciam enterradas na Europa e nos EUA. (RODRIK, 2011).

E com a crise financeira sistêmica desencadeada pela desvalorização dos ativos subprimes americanos em 2008, a economia mundial apresenta baixas taxas de crescimento, elevada instabilidade financeira, e tendência à deflação de preços das commodities e bens industrializados, dado o excesso de oferta de produtos e a capacidade ociosa de diversos setores industriais. O Fundo Monetário Internacional (FMI) prevê para 2016 uma expansão de 3,4\% da economia mundial (2,1\% para países desenvolvidos e 4,3\% para países emergentes). Desde 2012 a economia mundial expõe baixo dinamismo nos países emergentes, contrariando o ciclo expansionista de 2003-2007, quando cresceu a taxas superiores a 5\%. Os principais motivos são contração da demanda puxada 
pela desaceleração da China, queda nos preços das principais commodities, afrouxamento monetário, volatilidade dos mercados financeiros, desvalorização das moedas, diminuição do crédito e fuga de capitais com a sinalização de alta da taxa de juros nos EUA. Esse conjunto de fatores arrasta parte significativa dos países desenvolvidos e emergentes para um período de recessão ou de baixo dinamismo econômico. E as perspectivas da economia mundial para o fim dessa década se deterioram cada vez mais diante das transformações estruturais da $4^{\mathrm{a}}$ Revolução Industrial. (CINTRA, 2016).

Entre 1988-2008 o capital proveniente da tecnologia globalizada da era digital aumentou fortemente no mundo. A renda dos miseráveis dos países periféricos e emergentes elevou-se em 30\%, essencialmente na China e Índia. Todavia, os países desenvolvidos atravessam estagnação desde 2008. Na Europa e EUA, a renda da elite cresceu mais de $40 \%$, enquanto que das classes média e baixa subiu menos de $20 \%$. É enorme o ganho de renda para os que estão no topo da pirâmide dos países desenvolvidos (1\% a $10 \%$ da população), enquanto que a renda para a metade inferior das faixas desses países não cresceu nos últimos 20 anos. Na distribuição de renda europeia e americana não houve aumento de renda para os que estão na base, com a pressão sentida nos dois lados: abertura do mercado americano para a China e forte imigração para a Europa. Tais ganhos globais equânimes para a maioria das classes sociais dos países desenvolvidos, emergentes e periféricos, foram desiguais para as classes média e baixa das nações desenvolvidas, sendo denominados de "gráfico do elefante", como é demonstrado na figura que segue (MILANOVIC, 2016):

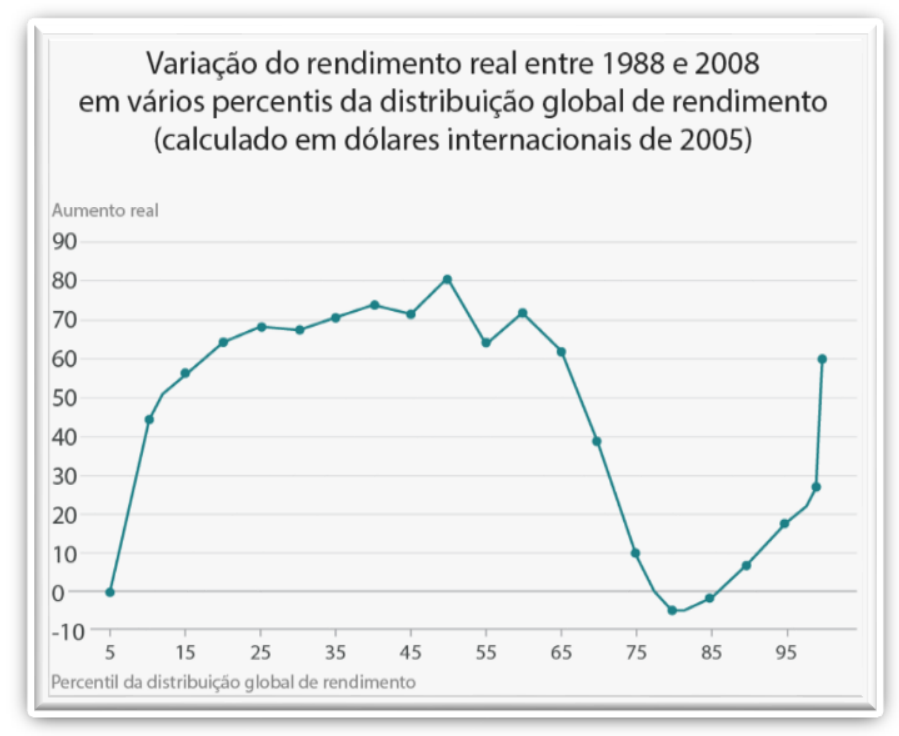


E quase 30 anos depois do Muro de Berlim, as consequências sociais do "gráfico do elefante" estão pondo em risco a democracia liberal. Sua principal ameaça é a ascensão do populismo político-fiscal, que mexe com os medos atávicos das pessoas em relação à imigração e ao terrorismo, proporcionados pela integração dos mercados de trabalho. A liberalização da economia global, ao mesmo tempo em que aumentou a competitividade econômica e ajudou a estabelecer democracia em países como Brasil, África do Sul e Índia, levou ao aprofundamento da desigualdade econômica, diminuição dos empregos e erosão dos salários dos trabalhadores das classes médias dos países desenvolvidos, e fez renascer os discursos nacionalistas e protecionistas com promessas vazias de proteger as pessoas das competições comerciais internacionais e dos avanços tecnológicos. (FUKUYAMA, 2016).

E como a $4^{\mathrm{a}}$ Revolução Industrial está ancorada na automatização extrema dos negócios, governos e vida privada, e na alta conectividade comunicacional, seus efeitos colaterais também serão inúmeros. A exemplo das outras revoluções, as máquinas, sensores, robótica e internet substituirão trabalhadores presenciais. Claro que novas modalidades de emprego serão criadas. Porém, em quantidades bem menores que nas revoluções anteriores, com a mão de obra barata e desqualificada contando cada vez menos na disputa global por empregos. Projeta-se até 2020, uma perda líquida de 05 milhões de empregos (7,1 milhões de empregos perdidos e 2,1 milhões de empregos criados em áreas especializadas como computação, matemática, arquitetura, engenharia, mídia, entretenimento). Ademais, na segunda fase da era digital as empresas terão mais liberdade para abrir e fechar fábricas em qualquer lugar do planeta, privilegiando fatores como o bom ambiente de negócios proporcionado pelo Estado e não o intervencionismo econômico na produção do PIB. Fundamental, portanto, a rápida conscientização das pessoas, empresas e governos sobre o tamanho, velocidade e impactos desse início de salto tecnológico, delineando-se questões centrais e suas possíveis respostas, como é o caso da oferta global de parcerias público-privadas visando desbloquear as oportunidades econômicas. (SCHAWB, 2015).

Por conseguinte, a $4^{\mathrm{a}}$ Revolução Industrial deve favorecer os países desenvolvidos em face do maior acesso à tecnologia, capacidade de inovação, mão de obra qualificada, cultura de integração, infraestrutura e logística, e capital disponível para investimentos, 
em detrimento dos países mais intensos em mão de obra barata, que tenderá a ser substituída por sistemas computacionais e robótica. Além disso, a passagem do comércio físico para o "virtual" terá impacto no crescimento das economias emergentes já que as cadeias produtivas tenderão a se encurtar, desencadeando outro período de verticalização da produção de alta tecnologia e de distribuição das tecnologias mais simples. Projeta-se ainda, que esse novo cenário econômico possa fortalecer o dólar como moeda de pagamentos e de reserva internacional em razão das vantagens competitivas detidas pelos EUA com as inovações tecnológicas e o respeito à propriedade intelectual. Enfim, baixo dinamismo em curto prazo, e mudança estrutural em médio e longo prazo, se constituem nos atuais desafios colocados para os países emergentes. Alguns poderão avançar; outros se distanciarão ainda mais dos países desenvolvidos; uns provavelmente sucumbirão. Ademais, a $4^{\text {a }}$ Revolução Industrial significa não uma época de mudanças, mas uma mudança de época, com alterações dos paradigmas técnico-científicos da dinâmica econômica global através de mudanças que ocorrerão dentro das estruturas e que irão rapidamente transformar a própria estrutura. (CINTRA, 2015).

E a recessão econômica de 2008-2016 fez os países desenvolvidos optarem por uma fase de "desglobalização", contaminando, em especial, os britânicos. No Reino Unido, mesmo os resultados econômicos sendo melhores do que França e Alemanha, com atração de investimentos estrangeiros e taxa de desemprego menor que a de seus vizinhos, o sentimento anti-Europa ainda permanece latente. Desde sua entrada no então Mercado Comum, em 1973, o Reino Unido foi o parceiro mais relutante da história da União Europeia. Governos de diferentes orientações ideológicas tentavam conter a demanda por "uma união cada vez mais próxima" vinda de Bruxelas. O Reino Unido, por exemplo, não faz parte da Zona do Euro (moeda única), muito menos da área Schengen, em que não há necessidade de apresentação de passaportes nas fronteiras do bloco comunitário.

O processo histórico que levou ao Brexit responde a um espírito nacionalista entre os países do Reino Unido, às vezes pulsante, outras vezes absconso. O Brexit poderá causar uma grave crise existencial na identidade da União Europeia em face do aumento dos atos de xenofobia e de ódio racial contra os imigrantes europeus e de outros continentes, tanto pelas perdas econômicas das classes média e baixa dos países desenvolvidos, como pelos atentados terroristas que pululam na Alemanha, França, 
Bélgica, Espanha e Grã-Bretanha. Teme-se que o resultado do plebiscito inspire outros países a repensar suas relações com o bloco comunitário, optando pela porta de saída. Afinal, nenhum dos 28 países-membros do bloco europeu tinha decidido deixá-lo para caminhar isoladamente.

\section{ANTI-POLÍTICA, NACIONALISMO E XENOFOBIA NOS MOVIMENTOS DESGLOBALIZANTES}

Consultas populares (plebiscito, referendo, recall) por terem forte carga de emoção podem expressar resultados indesejados. Nunca antes o destino de um país sem crise econômica, beligerância interna ou em processo bélico (numa única votação de eleitores desiludidos e mal-informados) mudou tanto um continente. É a "síndrome da fadiga democrática", o conjunto de sintomas que inclui impopularidade quase universal dos parlamentos, enfraquecimento dos partidos, confusões ideológicas do sistema partidário, crise de representatividade e rebelião contra a classe política, e consultas populares tectônicas (VAN REYBROUCK, 2016). Mesmo sendo decisão de um eleitorado mais cético do que fanático, com os partidos do Reino Unido divididos a direita e a esquerda, houve definição pela "religião secular", ou seja, a ideia de que a história tem uma orientação constante numa direção. Uma ilusão evolutiva rumo a um estado de coisas em harmonia com um ideal (ARON, 2016). No caso, o "destino manifesto" do Reino Unido a ser seguido isoladamente, sem mais necessitar da União Europeia.

O plebiscito sobre a União Europeia era demanda antiga do Partido Conservador. Em 2015, foi promessa de reeleição do primeiro-ministro britânico David Cameron, tendo que materializá-la em 2016. Todavia, as autoridades europeias estiveram ocupadas demais com a crise da Zona do Euro (sobretudo a grega), a anexação da Criméia pela Rússia, a guerra civil na Síria, o enorme fluxo de refugiados, e os atentados terroristas que ameaçavam as principais capitais europeias para dar a devida atenção ao polêmico debate britânico. O voto pelo Brexit ganhou nas áreas afetadas pela globalização: desindustrializadas e que sofreram desmonte das fontes tradicionais de emprego. A maioria dos eleitores do Brexit queria reduzir a imigração (77\%), era interiorana, mais idosa, não tinha ensino superior e representava classes médias e baixas com renda anual 
inferior a 25 mil libras, acirrando diferenças geográficas, etárias, econômicas e educacionais entre segmentos sociais e impactando nas liberdades comerciais e de movimento que beneficiam mais as classes altas. Tal eleitorado tem aversão a refugiados e imigrantes do bloco comunitário, esses, advindos majoritariamente da Romênia, Polônia, Espanha, Portugal, Bulgária e Eslováquia. Entre 1993-2014, os estrangeiros vivendo no Reino Unido passaram de 3,8 milhões para 8,3 milhões, com 05 milhões não sendo cidadãos britânicos, e apenas 03 milhões sendo imigrantes europeus. (TURRER \& PEROSA, 2016).

Contudo, o "euroceticismo" não é exclusividade dos britânicos, nem bandeira exclusiva da direita ou da esquerda. Quase metade dos europeus (42\%) concorda que alguns poderes devem ser devolvidos aos governos nacionais. Como Bruxelas ameaçasse a soberania dos países do bloco, já que os membros da Comissão Europeia não são escolhidos diretamente pelo voto da população, mas, ainda assim, os europeus precisam se sujeitar às leis criadas por tais burocratas. Temas como agricultura, políticas de competição e patentes são de decisão exclusiva do bloco. E como na Zona do Euro (19 países) o problema maior é o desemprego, os militantes do Brexit argumentaram que as regulações da União Europeia custavam semanalmente ao país 600 milhões de libras esterlinas, além dos 13 bilhões de libras de contribuição anual. As propostas de se livrar dos compromissos com a União Europeia, e assim, liberar 350 milhões de libras para o sistema de saúde pública e controlar o fluxo de imigrantes foram bem aceitas pelos eleitores. (BARBOSA \& MONTENEGRO, 2016).

A retórica anti-imigração venceu até o medo da recessão econômica, embora muitos eleitores não tivessem ideia do que de fato é a União Europeia, e faltem evidências concretas de como o Reino Unido independente conseguirá restringir a imigração de europeus sem perder o acesso ao Mercado Comum (VENTICINQUE, 2016). A integração de imigrantes no Reino Unido nunca foi tarefa fácil. E com o plebiscito, uma maioria silenciosa teve a oportunidade de manifestar sua insatisfação com a imigração de europeus e refugiados. No raciocínio de quem votou pela saída da União Europeia, o aumento do controle da imigração era tão importante que justificava perdas financeiras, quedas na balança comercial, incertezas econômicas e dificuldades na transição para um Reino Unido independente da Europa. 
E vários outros países têm testemunhado o crescimento de movimentos nacionalistas que se nutrem da rejeição à União Europeia, em face da aversão aos imigrantes, medo do terrorismo, e perdas de postos de trabalho. O bloco europeu registra $8,7 \%$ de desemprego, taxa que chega a ser quatro vezes maior entre os jovens da Espanha e Grécia. Politicamente, os efeitos do Brexit incentivaram a líder da extrema-direita francesa Marine Le Pen a também desferir discursos populistas, ultranacionalistas e isolacionistas, além de xenófobos e racistas, sobretudo contra imigrantes e muçulmanos. Le Pen busca realizar entre os franceses um plebiscito semelhante ao britânico: o Frexit. Plataforma muito semelhante tem o magnata Donald Trump, o presidente republicano dos EUA, que prometeu "fazer a América grande outra vez", proibindo a entrada de muçulmanos no país, deportando 11 milhões de imigrantes ilegais e erguendo um muro na fronteira com o México. O chefe do Partido de Liberdade Holandesa, Geert Wilders, proclamou que a Holanda será a próxima a sair da União Europeia, alémem da Suécia ter cunhado neologismo similar: Swexit. (WATKINS, 2016).

O Brexit representa uma tendência anti-política ou anti-establishment (ordem ideológica, econômica, política e legal que constitui uma sociedade ou um Estado) estimulada pela crise de 2008. Na Grécia, o Syriza foi eleito em 2015 com uma plataforma esquerdista que rejeitava medidas de austeridade fiscal da União Europeia. Mesmo não saindo da Zona do Euro e realizando o programa econômico europeu, a crise grega causou boa dose de "euroceticismo". Em 2016, a Itália elegeu duas prefeitas Virginia Raggi (Roma) e Chiara Appendino (Torino) do Movimento 5 Estrelas, criado em 2009 pelo humorista Beppe Grillo, até então considerado um "voto de protesto". O mesmo vale para a ascensão do Podemos, na Espanha. Movimentos anti-políticos fora da Europa ocorrem desde 2013 na Turquia, Colômbia, Argentina, Malásia e Brasil. Em 2015, depois de escândalos de corrupção, a Guatemala elegeu o comediante Jimmy Morales para a Presidência, e em 2016, as Filipinas escolheu como presidente o sanguinário Rodrigo Duterte. (YOUNG \& GARMAN, 2016).

A importância do Reino Unido no bloco europeu se dava não somente por sua condição de segunda nação mais rica da Europa e quinta economia mundial, mas por representar uma voz pela abertura de mercados e liberdade de relações comerciais, 
tradições britânicas com o resto do mundo. A saída do Reino Unido enfraquece o status quo da Europa de potência econômica integrada, altera o balanço de poderes na União Europeia e provoca fortes reações anti-Europa, colocando sob risco a integração do "edifício europeu".

\section{CONSIDERAÇÕES FINAIS}

A somatória dos "arquétipos jurídicos civilizatórios", como a criação da ONU, a proclamação da DUDH e a integração europeia deram vazão histórica para o aparecimento dos “eventos-fenômenos" no pós-século especial, no caso, a queda do Muro de Berlim, a globalização, e as fases da era digital entre os anos 1980 e o breve século XXI. A vitória dos valores políticos ocidentais com o fim da Guerra Fria, em especial, democracia representativa, economia de mercado e direitos humanos, e as mudanças tecnológicas e comportamentais da era digital impulsionadas pela globalização aumentaram a competitividade econômica e comercial das nações, trazendo a perspectiva de um mundo integrado em espaços institucionais democráticos e comuns.

Com a liberalização da economia global, os países desenvolvidos, emergentes e periféricos tiveram investimentos produtivos, incremento de renda e melhoria nos indicadores sociais. Todavia, os efeitos do "gráfico do elefante" demonstram o aprofundamento da desigualdade econômica, a diminuição dos empregos, e a erosão dos salários dos trabalhadores das classes média e baixa dos países desenvolvidos. Tal desempenho negativo desses segmentos sociais gerou uma perigosa onda desglobalizante e vem pondo a democracia liberal em risco. Cresce na Europa, EUA e países emergentes movimentos populistas de matizes anti-política e anti-austeridade fiscal, reforçando os medos atávicos em relação a imigrantes e ao terrorismo, através de discursos nacionalistas, xenófobos e com promessas vazias de proteger as pessoas da competição comercial internacional e do avanço tecnológico.

Entre 1951-2016, a União Europeia vinha realizando de forma contínua e ascendente a "transição do Estado nacional para o passado". O bloco comunitário europeu representa um projeto institucional de paz, democracia e colaboração econômica entre as 
nações num mundo sem fronteiras e barreiras comerciais, e em que a definição das identidades de cidadania não mais se limita ao lugar onde o indivíduo nasce. O Brexit simboliza um duro golpe contra o projeto integracionista mais ambicioso do planeta desde o fim da II Guerra Mundial. E como efeitos nefastos diretos do Brexit espera-se a diminuição da confiança política no projeto regional europeu, em curto prazo, a configuração de um cenário de incertezas econômicas que afugentará investidores, em médio prazo, e o crescimento do nacionalismo, da xenofobia e do isolacionismo das nações, em longo prazo. Percebe-se, assim, que em pleno processo de globalização e na segunda fase da era digital ainda existem espaços políticos no mundo para discursos à direita e à esquerda que põem em risco os ideias democráticos e configuram um dilema inimaginável para o respeito universal aos direitos humanos.

\section{REFERÊNCIAS}

ARON, Raymond. O ópio dos intelectuais. São Paulo: Três Estrelas, 2016.

AZEVEDO, Ivo Sefton de. Direito internacional público. Porto Alegre: Acadêmica, 1982.

BARBOZA, Mariana \& MONTENEGRO, Raul. O fim de uma era. Isto É. Ed. n 2.429. São Paulo: Três, 29 jun. 2016. p. 44-50.

BONAVIDES, Paulo. Curso de direito constitucional. São Paulo: Malheiros, 1994.

CERVO, Amado \& BUENO, Clodoaldo. História da política exterior do Brasil. São Paulo: Ática, 1992.

CINTRA, Marcos Antonio Macedo. A crise econômica mundial e a quarta Revolução Industrial. In: Blog Carta Capital. São Paulo, 25 fev. 2016. Disponível em: http:///www.cartacapital.com.br/blog. Acesso em: 21 jul. 2016.

COULON, Jocelyn. Soldiers of diplomacy: The United Nations, peace keeping and the new world order. Toronto: University of Toronto Press, 1998.

FASULO, Linda. Aninsider's guide to the UN. New Haven: Yale University Press, 2009.

FERRARI, Bruno. Uma nova revolução industrial. Época. Ed. n 944. São Paulo: Globo, 18 jul. 2016. p. 52-55.

FRIEDMAN, Thomas. O mundo é plano: uma breve história do século XXI. Rio de Janeiro: Objetiva, 2009. 
FUKUYAMA, Francis. Há chance de o Reino Unido se esfacelar. Época. Ed. nº 941. São Paulo: Globo, 27 jun. 2016. p. 46-48.

GORDON, Robert. The rise and fallof american growth: the US standard of living since the Civil War. Princeton: Princeton University Press, 2016.

HENIG, Ruth. O Tratado de Versalhes 1919-1933. São Paulo: Ática, 1991.

JENKINS, Henry. Cultura da convergência. São Paulo: Aleph, 2009.

KENNEDY, Paul. The parliament of man: the past, presenta nd future of the United Nations. New York: Random House, 2006.

KISSINGER, Henry. Diplomacia. Rio de Janeiro: Francisco Alves, 2001.

MANCINI, Federico. The making of a constitution of Europe. In: Common Market Law. London, $n^{\circ} 26,1989$. p. 595-614.

MEISLER, Stanley. United Nations: the first fifty years. New York: Atlantic Monthly Press, 1995.

MILANOVIC, Branko. Global inequality: a new approach for the age of globalization. Boston: Harvard University Press, 2016.

MIRES, Charlene. Capital of the world: the race to host the United Nations. New York: New York University Press, 2013.

MÖLLER, Josué Emilio. A fundamentação ética-política dos direitos humanos. Curitiba: Juruá, 2008.

RODRIK, Dani. The globalization paradox: democracy and the future of the world economy. New York: W.W. Norton, 2011.

SCHWAB, Klaus. A quarta revolução industrial. São Paulo: Edipro, 2016.

SEINTEFUS, Ricardo. Manual das organizações internacionais. Porto Alegre: Livraria do Advogado, 1997.

SIMON, Denys. Le système juridique communautaire. Paris: PUF, 1998.

TURRER, Rodrigo \& PEROSA, Teresa. O brado britânico. Época. Ed. nº 941. São Paulo: Globo, 27 jun. 2016. p. 32-39.

VAN REYBROUCK, David. Against elections. The case for democracy. London: Bodley Head, 2016.

VENTICINQUE, Danilo. A ressaca de uma vitória silenciosa. Época. Ed. No 941. São Paulo: Globo, 27 jun. 2016. p. 40-42. 
VIANNA, Regina \& MOREIRA, Felipe. O papel atual das organizações internacionais e a inserção brasileira. In: Revista Jurídica. Guarapuava: Editora Faculdade Novo Ateneu, v. 1, 2001. p. 145-150.

WARD, Ian. A critical introduction to european law. London: Butterworths, 1996.

WATKINS, Nathalia. Depois do Brexit, o Frexit, o Swexit... Veja. Ed. n 2.484. São Paulo: Abril, 29 jun. 2016. p. 72-75.

XAVIER, Laécio Noronha. Políticas públicas de segurança. Fortaleza: LCR, 2012.

YOUNG, Cliff \& GARMAN, Christopher. A era da classe média raivosa. Época. Ed. nº 941. São Paulo: Globo, 27 jun. 2016. p. 44-45. 